balanced among various surgical approaches and infectious complications and the maximization of growth potential.

\section{References}

1. Anderson C, Butcher H Jr, Ballinger WF. Mycotic aneurysms. Arch Surg. 1974; 109:712-7.

2. Barth H, Moosdorf R, Bauer J, Schranz D, Akintürk H. Mycotic pseudoaneurysm of the aorta in children. Pediatr Cardiol. 2000;21:263-6.
3. Idir M, Denisi R, Parrens M, Roudaut R, Deville C. Endarteritis and false aneurysm complicating aortic coarctation. Ann Thorac Surg. 2000;70: 966-8.

4. Jaleleddine Z, Sana C, Faker G, Adel K. Infective endarteritis and false mycotic aneurysm complicating aortic coarctation. Ann Pediatr Cardiol. 2012; 5:197-9.

5. Grant P, Murala J, Kolli R, Numa A, Awad J, Dilley AV. Massive hematemesis in a child with undiagnosed aortic coarctation and mycotic aneurysm. J Thorac Cardiovasc Surg. 2006;132:1482-3.

\title{
Giant, pedunculated right atrial thrombus formation after surgical atrial septal defect repair
}

\author{
Sayqa Arif, MRCP, ${ }^{\mathrm{a}}$ Dincer Aktuerk, MRCS, ${ }^{\mathrm{a}}$ and David J. Barron, FRCS, ${ }^{\mathrm{b}}$ Birmingham, United Kingdom
}

Despite advances in percutaneous catheter-based interventions, surgical repair with direct suture or a patch is still required for large secundum and other types of atrial septal defect (ASD), with excellent results and a low mortality. ${ }^{1}$ Although rare, thrombotic complications secondary to atrial thrombus formation after surgical ASD repair have been previously reported. ${ }^{2-4}$ There is, however, no consensus regarding the optimal postoperative antiplatelet or anticoagulation regimen. We report a case of a giant right atrial (RA) mass unrelated to the ASD patch. A review of the literature and the clinical management of postoperative atrial thrombi are discussed.

\section{CLINICAL SUMMARY}

A 20-year-old man came to the hospital with palpitations and breathlessness. Results of clinical examination were unremarkable. Initial investigations, including an electrocardiogram and a chest radiograph, demonstrated no abnormalities. Eleven months previously, the patient had undergone primary surgical repair of a large secundum ASD with a bovine pericardial patch. The patient was advised to take low-dose (75 mg once daily) aspirin for 6 months after that operation. Transthoracic echocardiographic scans

From the University Hospital Birmingham NHS Trust, ${ }^{a}$ Birmingham, United Kingdom; and the Birmingham Children's Hospital, ${ }^{\text {b }}$ Birmingham, United Kingdom.

Disclosures: Authors have nothing to disclose with regard to commercial support.

Received for publication July 28, 2014; revisions received Oct 19, 2014; accepted for publication Nov 6, 2014; available ahead of print Dec 18, 2014.

Address for reprints: Sayqa Arif, MRCP, Department of Cardiothoracic Surgery, University Hospital Birmingham NHS Trust, Mindelsohn Way, Edgbaston, Birmingham B15 2TH, United Kingdom (E-mail: sayqa.arif@uhb.nhs.uk).

J Thorac Cardiovasc Surg 2015;149:e46-8

$0022-5223 / \$ 36.00$

Copyright (C) 2015 by The American Association for Thoracic Surgery

http://dx.doi.org/10.1016/j.jtcvs.2014.11.036 performed before hospital discharge and at 3-month routine clinical review revealed no evidence of residual leak and no significant cardiac abnormality.

On admission, transthoracic echocardiography demonstrated a large, spherical, pedunculated mass in the RA, the etiology of which was uncertain. Transesophageal echocardiography (Figure 1) confirmed a mobile mass attached to the anterior aspect of the superior vena cava at its entrance into the RA. The mass was highly mobile, suspended by a thin, linear attachment, and prolapsing into the tricuspid valve (Figure 1, $A$ ). Because of the size of the mass and the fact it was freely mobile, emergency surgery was performed. Intraoperative findings revealed a large spherical 6-cm mass arising from a thin, fibrous stalk attached to the lateral wall of the RA at the junction of the superior vena cava and the RA (Figure 2). The pedicle was not related to the septum or the ASD patch. Histologic evaluation of the mass revealed a bland ball thrombus, with no evidence of neoplasia. It was postulated that the original nidus for the thrombus was the tip of the central venous cannula inserted at the time of the original surgery, which allowed gradual, concentric layering of thrombus with time. A thrombophilia screen was undertaken and demonstrated no evidence of hypercoagulability. The patient made an uneventful recovery and received anticoagulation with warfarin for 6 months. Follow-up at 3 months after the removal of the mass demonstrated no evidence of intracardiac thrombus recurrence. Further transthoracic echocardiographic follow-up is planned in 6 months and annually thereafter.

\section{DISCUSSION}

Postoperative intra-atrial thrombus after surgical ASD closure has been observed as late as 8 years after the original 


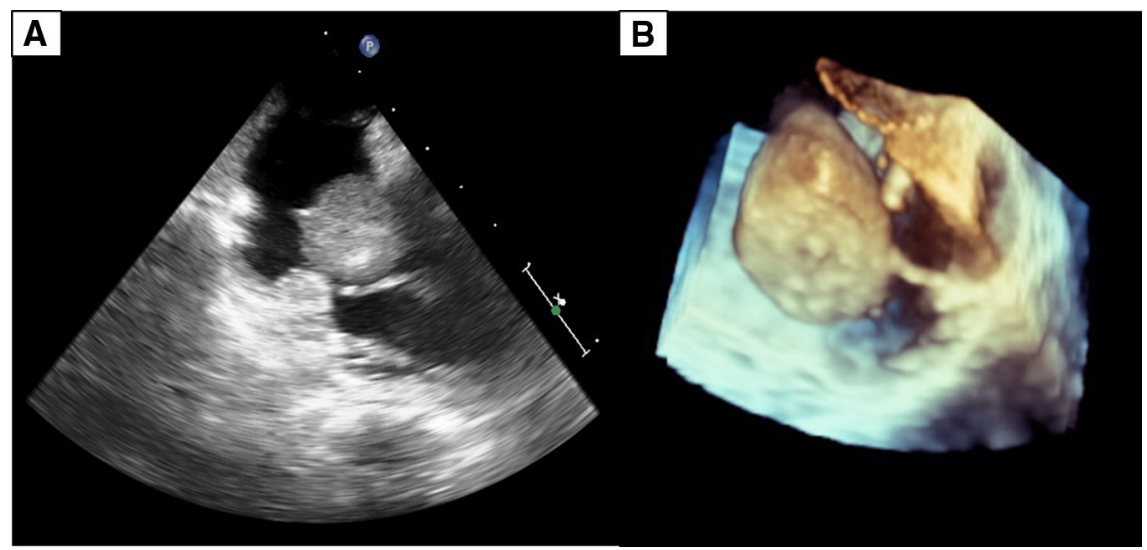

FIGURE 1. A, A 2-dimensional transesophageal image of the right atrial mass approaching the tricuspid valve. B, A 3-dimensional transesophageal image of the right atrial mass with stalk.

operation. Thrombus is usually reported as being related to the patch and is often associated with established atrial fibrillation or flutter. In most situations, cardiac surgery has been performed for excision of the mass and its exact nature determined by histopathologic examination. In the case presented here, the thrombus was unrelated to the patch and occurred in an otherwise healthy young man with no evidence of atrial arrhythmia. This case emphasizes the need for routine echocardiographic follow-up. Guidelines recommend regular echocardiographic surveillance after surgery, usually at 24 hours, 1 month, 6 months, 1 year, and then at regular intervals. ${ }^{5}$ There is no consensus regarding postoperative antiplatelet or anticoagulation therapy. Our institutional practice is treatment with single antiplatelet therapy for 6 months for all patients who have undergone surgical ASD patch repair.

Review of the literature demonstrates that there are no data regarding incidence of thrombus formation after surgical ASD repair, and it is therefore difficult to define the extent of the problem. Data are largely derived from isolated case reports. After this diagnosis of intracardiac thrombus, we elected to provide anticoagulation for our patient with a vitamin $\mathrm{K}$ antagonist. The duration of anticoagulation is to be determined by resolution of thrombus on subsequent serial echocardiographic scans. Others have also raised the possibility of commencing anticoagulation therapy in patients after patch ASD repair. ${ }^{4}$ Accepting that there is little guidance in the literature as to the optimal regimen after surgical ASD repair, it may be reasonable to consider antiplatelet therapy for several months in patients undergoing patch ASD repair. If subsequent intracardiac thrombus formation occurs despite antiplatelet therapy, anticoagulation is warranted for some period afterward, until resolution of the thrombus occurs. This subjects merits further attention and discussion in view of the potential serious consequences of intracardiac thrombus development.

\section{References}

1. Visconti KJ, Bichell DP, Jonas RA, Newburger JW, Bellinger DC. Developmental outcome after surgical versus interventional closure of secundum atrial septal defect in children. Circulation. 1999;100(19 Suppl):II145-50.

2. Yilmaz M, Gurlertop Y, Erdogan F. Right atrial thrombus following closure of an atrial septal defect. Heart. 2003;89:726.

3. Sheikh AY, Schrepfer S, Stein W, West J, Lombard J, Burdon T, et al. Right atrial mass after primary repair of an atrial septal defect: thrombus masquerading as a myxoma. Ann Thorac Surg. 2007;84:1742-4.
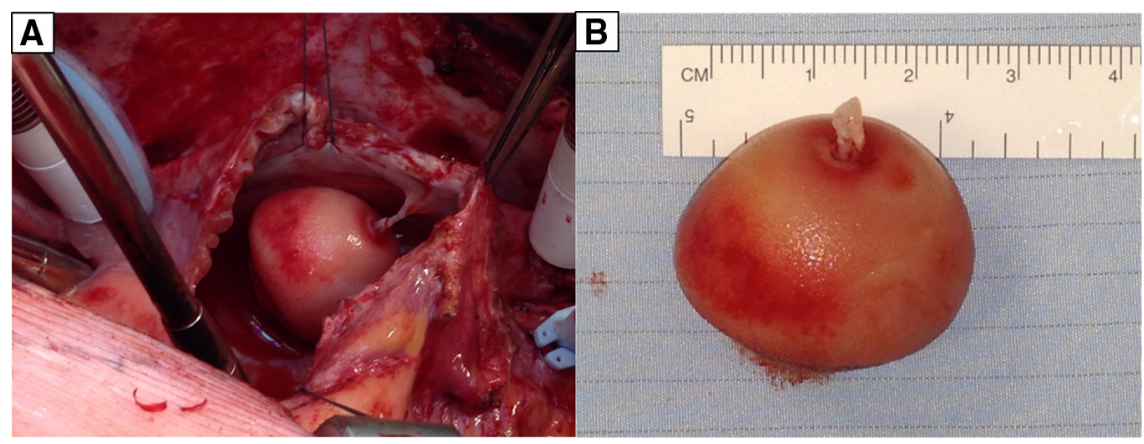

FIGURE 2. A, The right atrial mass in situ. B, The right atrial mass excised. 
4. Sun HR, Tang H, Song HB. Ball thrombus in the right atrium after patch closure of atrial septal defect. Heart Lung Circ. 2014;23:e152-3.

5. Warnes CA, Williams RG, Bashore TM, Child JS, Connolly HM, Dearani JA, et al. ACC/AHA 2008 guidelines for the management of adults with congenital heart disease: a report of the American College of Cardiology/American Heart Association Task Force on Practice Guidelines (writing committee to develop guidelines on the management of adults with congenital heart disease). Circulation. 2008;118:e714-833.

\title{
Cor triatriatum dexter: A rare cause of myocardial infarction and pulmonary embolism in a young adult
}

\author{
Syed T. Hussain, MD, Kwabena Mawulawde, MD, Robert D. Stewart, MD, and Gösta B. Pettersson, MD, PhD, \\ Cleveland, Ohio
}

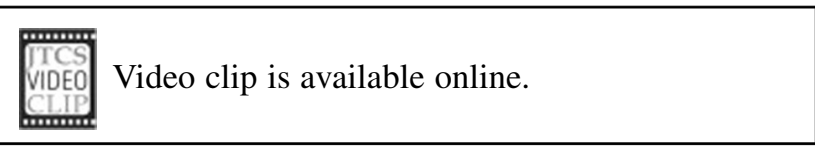

Cor triatriatum dexter (CTD) is an extremely rare congenital cardiac anomaly in which the right atrium (RA) is divided into 2 chambers by a membrane; it is caused by persistence, instead of the usual regression, of the right valve of the sinus venosus and is frequently associated with right-sided cardiac abnormalities. ${ }^{1}$ CTD has varying

From the Department of Thoracic and Cardiovascular Surgery, Heart and Vascular Institute, Cleveland Clinic, Cleveland, Ohio.

Disclosures: Authors have nothing to disclose with regard to commercial support.

Received for publication Nov 11, 2014; accepted for publication Nov 28, 2014; available ahead of print Jan 23, 2015.

Address for reprints: Gösta B. Pettersson, MD, PhD, Department of Thoracic and Cardiovascular Surgery, Cleveland Clinic, 9500 Euclid Ave/Desk J4-1, Cleveland, OH 44195 (E-mail: petterg@ccf.org).

J Thorac Cardiovasc Surg 2015;149:e48-50

$0022-5223 / \$ 36.00$

Copyright (c) 2015 by The American Association for Thoracic Surgery

http://dx.doi.org/10.1016/j.jtcvs.2014.11.078 clinical manifestations, depending on the degree of partitioning or septation of the RA, from completely asymptomatic to severe right-sided heart failure. ${ }^{2-4} \mathrm{We}$ present a case of CTD in a young adult presenting with myocardial infarction and pulmonary embolism who eventually underwent successful surgical excision of the membrane and removal of RA and tricuspid valve thrombus.

\section{CLINICAL SUMMARY}

A 22-year-old woman presented with acute-onset leftsided chest pain and shortness of breath and was diagnosed with a small subsegmental pulmonary embolism and placed on enoxaparin. Lower-extremity Doppler was negative. Coagulation studies, including Factor V Leiden mutation, performed because of her family history of pulmonary embolism, were all negative. Echocardiography revealed severe RA enlargement, a thickened tricuspid valve, and a large atrial septal defect with right-to-left shunt. She had a history of asthma and peripheral cyanosis, and she had suffered an inferior-wall myocardial infarction with
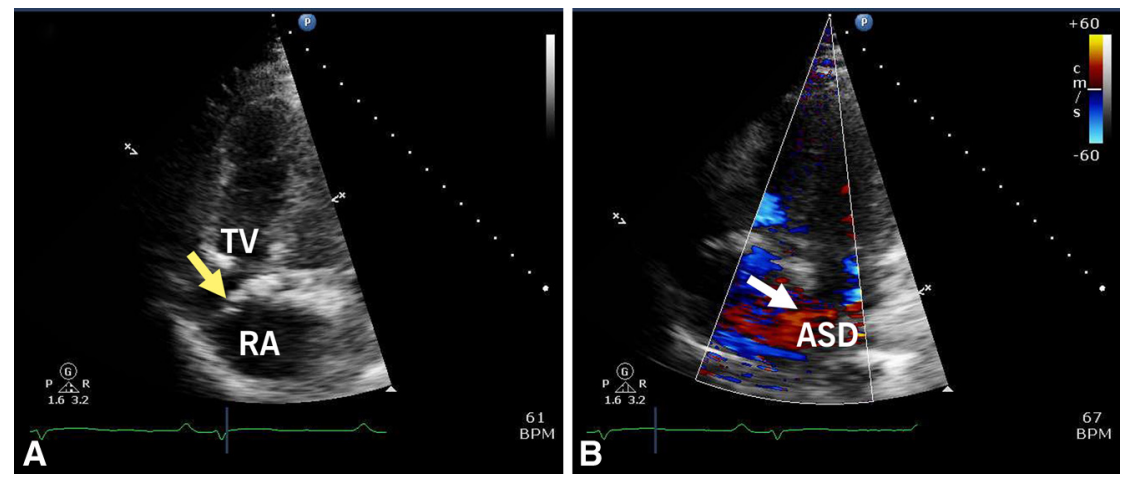

FIGURE 1. Preoperative echocardiogram. A, The thick membrane in the right atrial cavity (yellow arrow) divides the right atrium into 2 chambers. B, Right-to-left flow across the atrial septal defect (white arrow). TV, Tricuspid valve; RA, right atrium; ASD, atrial septal defect. 